\title{
lonic Strength Effect on Malachite Green Adsorption onto Moroccan Montmorillonite Clay: Experimental Study and Theoretical Investigation
}

\author{
EL HOUSSIEN AKICHOUH ${ }^{1 *}$, SAMIRA SALHI ${ }^{1}$, MOHAMED KHOUTOUL ${ }^{2}$, \\ MOHAMED EL MIZ ${ }^{1}$, ALI EL BACHIRI ${ }^{1}$ and ABDESSELAM TAHANI ${ }^{1}$ \\ 'Laboratory of Physical Chemistry of the Natural Resources and Environment, Faculty of Science, \\ Mohammed First University, Oujda, Morocco. \\ 2Laboratory of Applied Chemistry \& Environment, Faculty of Science, Mohammed First University, \\ Oujda, Morocco. \\ ${ }^{*}$ Corresponding author E-mail: akhoussein @ gmail.com \\ http://dx.doi.org/10.13005/ojc/360109
}

(Received: October 23, 2019; Accepted: January 10, 2020)

\section{ABSTRACT}

\begin{abstract}
The equilibrium adsorption process of Malachite green(MG) from an aqueous solution using Sodic Moroccan Montmorillonite Clay (Na-MMC) has been investigated under various experimental conditions. The effect of several inorganic salts $(\mathrm{LiCl}, \mathrm{NaCl}, \mathrm{KCl}$, and $\mathrm{CsCl}$ ) on malachite green adsorption at different ionic strength by sodic montmorillonite as well as the $\mathrm{pH}$ effect were investigated through a number of batch adsorption experiments. The dye concentration in the solution before and after adsorption was measured spectrophotometrically. The experimental isotherm data show that the maximum removal of $\mathrm{MG}$ was observed at $\mathrm{pH}$ in the rang 8-10. The adsorbed amount increases with the concentration of the sodium or lithium, however it decrease with cesium or potassium salts. A theoretical explanation of MG adsorption and ionic strength effect was given based on data modeling developed by Nir and Co. also. Geometry optimizations of MG molecule to get a better insight into structure geometry and reactivity were carried out by DFT calculations.
\end{abstract}

\section{INTRODUCTION}

The increasing use of organic dyes endangers the environment and poses health problems for humans and aquatic animals. Consequently, the risk of pollution increases if the depollution processes do not follow the rhythm of this evolution. Dyes are water-soluble and exhibit inherent chemical structure that is stable to photodegradation and biodegradation'. A number of physicochemical and biological methods have been reported for removal of dyes from waste wate $^{2,3}$. Adsorption has been widely recognized as effective and low-cost method to abet dye waste water even at low concentration ${ }^{4}$. Various types of adsorbent materials are available: activated carbon, silica, natural polymeric materials, sewage sludge, clays $^{5,6}$. However the quality of the adsorbent must

This is an Open Access article licensed under a Creative Commons license: Attribution 4.0 International (CC- BY). Published by Oriental Scientific Publishing Company @ 2018 
meet the scientific and economic criteria, such as the quantity to be treated (high cationic exchange capacity), favourable conditions for the elimination, regeneration and above all a very low cost process ${ }^{7}$. Recent studies show several attempts to boost the adsorption performance of malachite green that is present in effluent by its use as antifungal, anti-bacterial, and anti-parasitical and also by its widely used as a direct dye for silk, wool, jute and leather ${ }^{8,9}$.

The use of clays to remove this type of polluting molecules is one of the efficient and economical methods ${ }^{10}$. In a wide variety of research, the bentonite (or montmorillonite) is the most used class $^{2,11,12}$. The montmorillonites clay is one of the minerals belongs to the smectite family, This type of phyllosilicates consists of two tetrahedral layers framing an octahedral layer (phyllosilicates 2: 1) ${ }^{13}$.

Montmorillonites surface promote a good physical properties for cations adsorption; the existence of negative charges on their surface gives them an adsorption capacity with cations and particularly with organic cations ${ }^{14,15}$.

Organic cations are adsorbed on montmorillonite surface by the cationic exchange with the hydrated exchangeable cation, which balance the negative intrinsic charge of surface. Other types of associations may also be present in the adsorption of organic molecules on the surface of montmorillonite, for example, van der Waals and hydrogen bonds ${ }^{16-18}$. Their importance also depends on such factors as the nature of organic molecule, its functional groups present, the nature of exchangeable cation, the temperature, the $\mathrm{pH}$, the ionic strength and the nature of the ions present in the dispersion $\left(\mathrm{Na}^{+}, \mathrm{K}^{+}, \mathrm{Cs}^{+} \ldots\right)^{11,12}$. However, to date, the effect of ionic strength on this type of adsorption has been rarely studied; Giora Rytwo and his groups ${ }^{15,19-22}$ are the only ones who studied this effect experimentally and theoretically by developing a model applying a Gouy-Chapman-Stern (GCS) model for adsorption of organic cations ${ }^{23,24}$. The main concept of this model is developed in the theoretical part below.

With the development of density functional theory (DFT) ${ }^{25}$, electronic properties of ground states can be calculated with good accuracy. Theoretical calculations (DFT) at B3LYP level have been carried out aiming to investigate the structure geometry of the MG dye, electronic properties and their dependences. We combined some theoretical descriptor reactivity calculated with DFT with experimental results of MG-MMC interactions.

In this work, a Moroccan sodic Montmorillonite clay (obtained by the purification and treatment of raw clay extracted from the region of Nador) ${ }^{26}$, was characterized and tested as adsorbent for cationic MG dyes removal from aqueous solution. The evaluation of its potential as low cost adsorbents and the effect of ionic strength for adsorption of green malachite (MG) on sodic Montmorillonite (Na-MMC) will be shown. It is noteworthy that a variety of alkali metals (lithium, sodium, potassium and cesium) chlorides has been used. Interestingly, the effect of the concentration and the cation nature will be detailed on the equilibrium adsorption isotherm. The theoretical interpretation of the results is based on the modelling described at the top, using the coefficients of binding determined by Nir in $1986^{27}$. This study is an extension of previous research related to bentonite (montmorillonite) deposits from Morocco and their possible applications in the removal of pollutants from wastewater.

\section{MATERIALS AND METHODS}

\section{Materials}

\section{The adsorbate}

Malachite green used in this study was purchased from Merck (99\% pure) and used without further purification. Its molecular structure and some of its characteristics are illustrated in Table 1. Dye stock solution (2mmol. $\mathrm{L}^{-1}$ ) was prepared by dissolving accurately weighed quantity of the dye in double distilled water. Experimental dye solution of different concentrations was prepared by diluting the stock solution with suitable volume of double distilled water.

\section{The adsorbent}

The sodic Montmorillonite clay (Na-MMC) used in this work was prepared from crude bentonite extracted from a clay deposit in Nador region (northeast of Morocco). EL MIZ et al., carried out purification; sodium activation and characterization ${ }^{26,29,30}$. The mineralogical and chemical compositions of the samples are typical of bentonites, mainly consisting of montmorillonite. Table 2 summarizes the physico-chemical characteristics of our Na-MMC and that of Wyoming Na-montmorillonite SWy obtained from the Source Clays Repository (Clay Minerals Society, Columbia, MO) ${ }^{15}$. 
Table 1: Characteristics of Malachite Green (MG) ${ }^{28}$

\begin{tabular}{|c|c|}
\hline Dyestuff & Basic Green 4 (BG 4) \\
\hline IUPAC & $\begin{array}{l}\text { [4-[[4-(dimethylamino) } \\
\text { phenyl]phenylmethylidene] } \\
\text { cyclohexa-2,5-dien-1-ylidene] } \\
\text { dimethylazanium;chloride }\end{array}$ \\
\hline Commercial name & Malachite green \\
\hline C.I. number & 42000 \\
\hline Empirical formula & $\mathrm{C}_{23} \mathrm{H}_{25} \mathrm{~N}_{2} \mathrm{Cl}$ \\
\hline Appearance & Green crystalline powder \\
\hline Molecular weight & $364.9 \mathrm{~g} / \mathrm{moL}$ \\
\hline$\lambda_{\max }$ & $621 \mathrm{~nm}$ \\
\hline Solubility at $25^{\circ} \mathrm{C}$ & $40 \mathrm{~g} / \mathrm{L}$ \\
\hline Molecular structure & \\
\hline
\end{tabular}

Table 2: Physico-chemical characteristics of selected clays

\begin{tabular}{lcc}
\hline Characterization & $\begin{array}{c}\text { Nador } \\
\text { Na-Mont }\end{array}$ & $\begin{array}{c}\text { Wyoming Na- } \\
\text { montmorillonite SWy-1 }\end{array}$ \\
\hline CEC (meq $/ 100 \mathrm{~g})$ & 109 & 76.4 \\
Stot $\left(\mathrm{m}^{2} / \mathrm{g}\right)$ & 785 & 756 \\
\hline
\end{tabular}

\section{Methods}

\section{Theory}

Gouy-Chapman-Stern (GCS) adsorption model

Rytwo et al., developed the model presented here and based on the Gouy-Chapman-Stern theory ${ }^{15,23}$. It is associated with the equations established by Nir and Margulies 27,31 . Two types of equations, modelled the interaction between the charged surface of montmorillonite and organic cations.

The interaction between a negative site $\mathrm{P}^{-}$of clay and a cation $\mathrm{X}^{+}$:

$$
P^{-}+X_{i}^{+} \stackrel{\leftrightarrows}{\rightarrow} X_{i}
$$

The constant $\mathrm{K}_{i}$ of this reaction that translates the binding force (coefficient) for electrostatically associated is:

$$
K_{i}=\frac{\left[P X_{i}\right]}{\left[P^{-}\right] .\left[X_{i}^{+}(0)\right]}
$$

For the organic cations can have in addition, other interaction between these cations $\mathrm{Xi}$ and the neutral complex PXi produced by first interaction:

$$
P X_{i}+X_{i}^{+} \stackrel{\leftarrow}{\rightarrow} P X_{i 2}^{+}
$$

With The binding coefficient $0 \mathrm{i}$ is :

$$
\hat{\mathrm{K}}_{i}=\frac{\left[P X_{i_{2}}^{+}\right]}{\left[P X_{i}\right] \cdot\left[X_{i}^{+}(0)\right]}
$$

In all equations, we have, $X_{1}{ }^{+}(0)$ is the concentration of the cation at the surface and may be calculated upon knowing its concentration in the equilibrium solution $X_{1}(\infty)$, since the distribution of the cation as a function of its distance from the surface, depends on the electric potential.

For this, we may use Boltzmann's equation:

$$
\begin{aligned}
& X_{i}^{+}(0)=X_{i}(\infty) \cdot Y_{0}{ }^{Z_{i}} \\
& \text { With } \quad Y_{0}=\exp \left(-\frac{e \cdot \psi(0)}{k_{B} \cdot T}\right)
\end{aligned}
$$

Where: $\mathrm{e}$ is the elementary charge, $\mathrm{Zi}$ is the valence of the ion, being positive for a cation and negative for an anion, $\psi(0)$ is the surface potential, $k_{B}$ is the Boltzmann constant, $T$ is the absolute temperature, and $X_{i}(\infty)$ is the molar concentration of cation $\mathrm{i}$ in the solution heart, far from the surface. The potential value of the clay surface varies with the amount of adsorbed cations added. When the surface is negatively charged one has $\mathrm{Xi}(0)>\mathrm{Xi}(\infty)$, if the amount of dye added is greater than the cationic exchange capacity (CEC) a charge reversal produced on the surface of the clay, consequently the electrostatic interactions repulsive causes the immigrations of the cations towards the core of solution or $\mathrm{Xi}(0)<\mathrm{Xi}(\infty)$.

\section{Computational method}

The computations were performed utilizing the GAUSSIAN 09 program pack ${ }^{32}$, GaussView program ${ }^{33}$ were used to visualisation. The ground state geometries were totally optimized using the hybrid B3LYP functional ${ }^{34,35}$ with the 6-31G (d) basis set. To account for the solvent effect, the single point calculation was carried out at the same theory level, with the aid of the integral equation formalism polarizable continuum model (IEFPCM) ${ }^{36}$

\section{Batch Adsorption}

To measure the dyes adsorption isotherms, a quantity $40 \mathrm{mg}$ of the $\mathrm{Na}-\mathrm{MMC}$ was added to 50 $\mathrm{mL}$ solution of the prepared dye solution in $250 \mathrm{~mL}$ Erlenmeyer flasks. The final volume was brought to $100 \mathrm{~mL}$ by adding either the alkali chloride solution to study the effect of ionic strength, or a double 
distilled water to study the $\mathrm{pH}$ effect. The flasks were sealed and kept at $25 \pm 1^{\circ} \mathrm{C}$ under continuous agitation (300 rpm) up to the equilibrium (for 12 hours). After the reaction period, the supernatant was separated by centrifugation at $9000 \mathrm{rpm}$ for 15 min, the residual concentration in the supernatant was determined. The dye concentration in the raw and treated sample was determined by UV-Vis spectrophotometer (Shimadzu UV-1800 UV/Visible Scanning Spectrophotometer). The analyses were carried out at a wavelength of $619 \mathrm{~nm}$. The amount of equilibrium adsorption, Qe (meq/100 g), was calculated by Eq.7, and the percent of adsorption efficiency, $(A \%)$ was calculated as Eq.8 :

$Q_{e}=\frac{100 \cdot\left(C_{0}-C_{e}\right) \cdot V}{m}$
$A \%=\frac{\left(C_{0}-C_{e}\right) \cdot 100}{C_{0}}$

Where $\mathrm{C}_{0}$ and $\mathrm{C}_{\mathrm{e}}(\mathrm{mM})$ are the liquid-phase concentrations of dye at initial and equilibrium, respectively, $\mathrm{V}(\mathrm{L})$ is the volume of the solution and $\mathrm{m}(\mathrm{g})$ is the mass of dry prepared sorbent used.

\section{X-Ray Diffraction}

From the samples obtained after the centrifugal separation described above, $2 \mathrm{~mL}$ of suspension were deposited on glass microscope slides and dried. The basal spacing was measured using a PANalytical Diffractometer: XPERT-PRO, Copper Anticathode Ceramic X-ray Tube, Generator Power at RX: $40 \mathrm{~mA}, 45 \mathrm{kV}$. The angular scan was performed in discrete steps of $0.05^{\circ}(2 \theta)$ with a counting time of 5 seconds per step.

\section{RESULTS AND DISCUSSION}

\section{Effect of the solution $\mathrm{pH}$}

The $\mathrm{pH}$ of the aqueous solution has a major effect on the protonation and deprotonation of the functional groups of the Montmorillonite surface. The effect of $\mathrm{pH}$ on adsorption of MG on $\mathrm{Na}-\mathrm{MMC}$ was examined through an agitation of $40 \mathrm{mg}$ of adsorbent with $100 \mathrm{~mL}$ of MG dye solution of $1,4 \mathrm{mmoL} / \mathrm{L}$ concentration at different $\mathrm{pH}$ values from 3 to 11. The solution $\mathrm{pH}$ was adjusted by $\mathrm{HCl}$ or $\mathrm{NaOH}$ solution.

Using Marvin Sketch ${ }^{37}$, which is a software for structure property prediction and calculation, we have calculated the cationic MG charges at different $\mathrm{pH}$, the results are shown on Fig. 1. From the obtained results, we observe that the adsorption of $M G$ increases with the initial $\mathrm{pH}$ values.

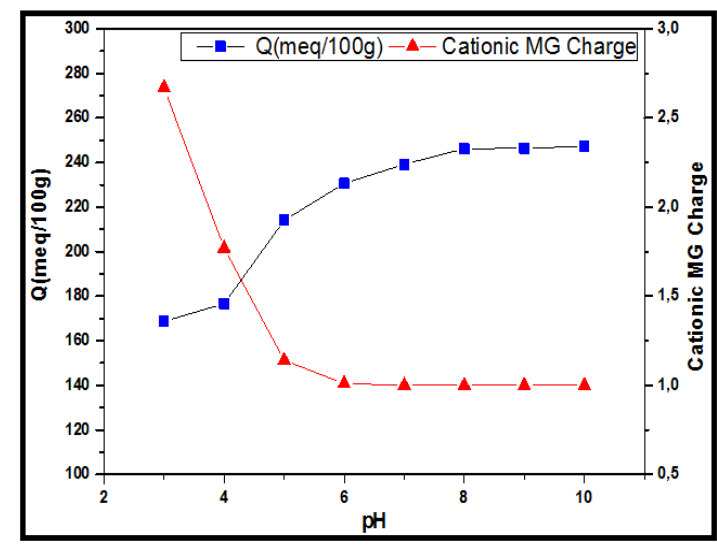

Fig. 1. Effect of pH on adsorption of MG by Na-MMC

The adsorption of MG on the Na-MMC increases, from 176.7 to $249 \mathrm{meq} / 100 \mathrm{~g}$ while the $\mathrm{pH}$ value increases from 4 to 8 . The previous studies have shown that at high $\mathrm{pH}$ values, the cations are adsorbed due to the negatively charged surface sites of the Montmorillonite ${ }^{2,38-40}$. In aqueous solution, the Montmorillonite surface hydroxyl site $(\mathrm{M}-\mathrm{OH})$, such as alumina, undergoes the protonation/deprotonation process $^{41}$. An alkaline environment gives rise to more negative charges on the Montmorillonite hydroxyl group's (Eq.10), which leads to an increase in the density of the negative charge on the external surface of the clay and consequently the MG adsorbed amount increase at higher $\mathrm{pH}$ value.

$$
\mathrm{M}-\mathrm{O}^{-}+\mathrm{H}_{2} \mathrm{O} \underset{\mathrm{H}^{+}}{\stackrel{\mathrm{HO}^{-}}{\leftrightarrows}} \mathrm{M}-\mathrm{OH} \underset{\mathrm{H}^{+}}{\stackrel{\mathrm{HO}^{-}}{\leftrightarrows}} \mathrm{M}-\mathrm{OH}_{2}^{+}
$$

Compared to other adsorbates, the significant observed increase of the MG adsorption with the $\mathrm{pH}$ value can be explained by the deprotonation of MG at higher $\mathrm{pH}$ value (Fig. 1) and, consequently, by the small positive charge density of $\mathrm{MG}$ at a higher $\mathrm{pH}$. This promotes nonspecific adsorption (Eq.3) after surface charge reversal ${ }^{31}$ and thereby increases the adsorbed amount at high $\mathrm{pH}$. More, this modeling shows that the MG charge is stable (at the value 1) when the $\mathrm{pH}$ is greater than 7 , it confirms the stability of the amount of MG adsorbed in this $\mathrm{pH}$ range (Fig. 1). Because the surface charge of montmorillonite in the presence of sodium remains constant $^{42}$ when the $\mathrm{pH}>7$. 


\section{Effect of initial malachite green concentration}

The effect of initial Malachite green dye concentration was studied at different initial MG dye concentrations in the range of 25-400 meq dye/100 $\mathrm{g}$ at $298 \mathrm{~K}$ with $0,04 \mathrm{~g}$ of $\mathrm{Na}-\mathrm{MMC}$ at the solution $\mathrm{pH}$. The results presented in Fig. 2 showed that the equilibrium percent of adsorption efficiency $A \%$ slightly increases with increasing initial dye concentration.

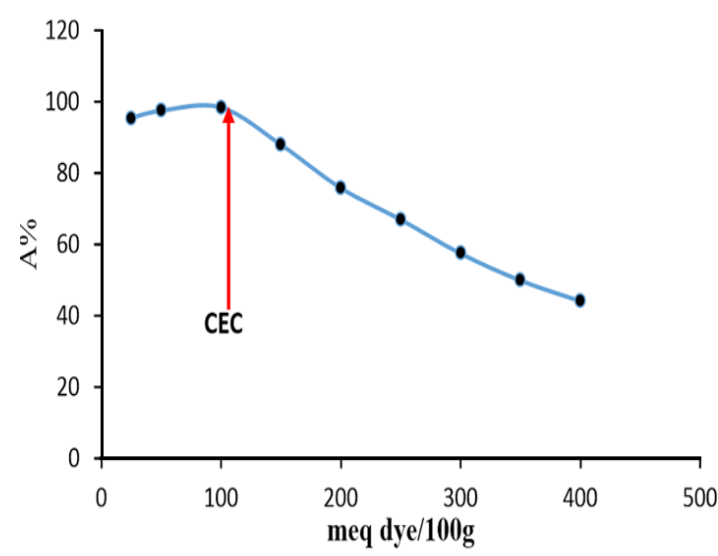

Fig. 2. The effect of the initial dye concentration onto equilibrium Na-MMC A\%

Afterwards, the adsorption capacity marks a sudden decrease with further increasing in the initial concentration of MG. Theoretically and according to the Boltzmann's law, the decrease of the adsorption percent with the increase in the initial dye concentration is attributed to the reduction of sites charged on the surface of the clay. This has been experimentally analyzed by using X-Ray diffraction (XRD). Tracking the 001 peak position by DRX has shown a displacement of this peak (Fig. 3), after adsorption, the basal distance increases, which indicates that the exchange process between sodium and MG was carried out.

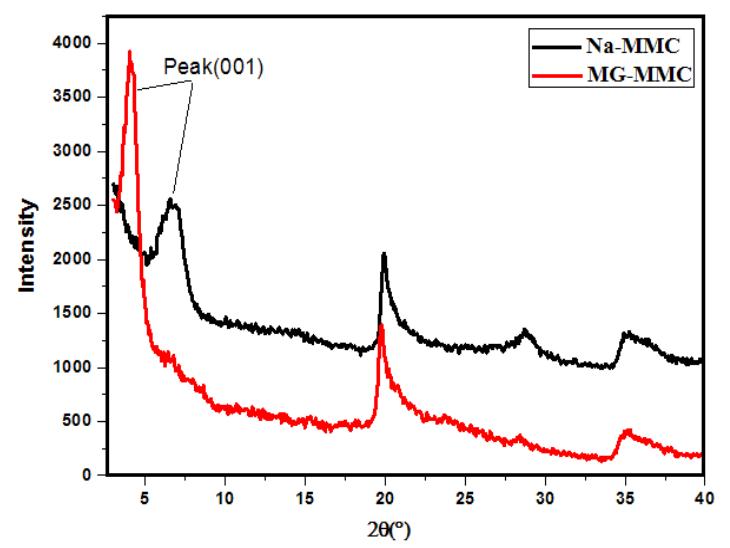

Fig. 3. X-Ray diffractograms of sodic montmorillonite (Na-MMC) and green malachite-montmorillonite (MG-Mont)
The measurement of the interlayer space distance or the basal spacing of the montmorillonite after adsorption, for each initial concentration of MG showed that this distance has a simulated variation by comparison with the percentage of the adsorption as shown in Fig. 4.

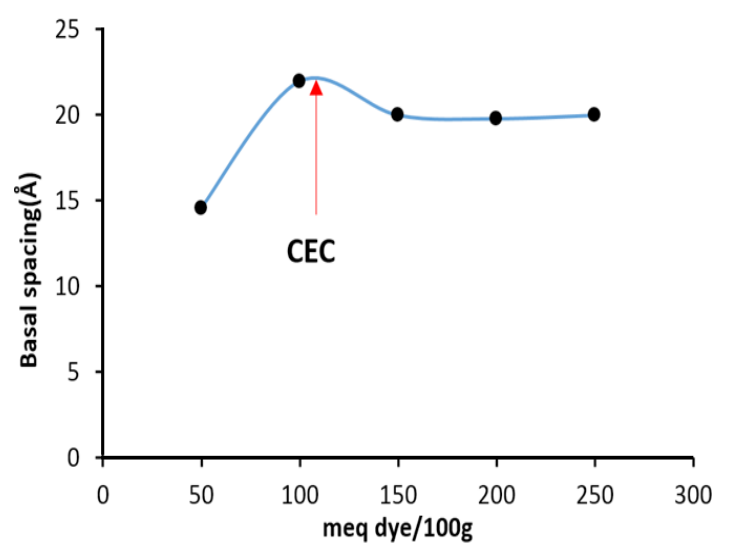

Fig. 4. Basal spacing of MG-Montmorillonite complexes at different initial dye concentration

In the range 0-100 meq/100 $\mathrm{g}$, where the adsorbed quantity is lower than the CEC, the increase in the basal space is explained by the replacement of the hydrated sodium cations by MG organic cations. However, a quantity of sodium ions compensates negative charges on the surface of the clay since the amount of dye is lower than Cation Exchange Capacity.

The measurement of the interlayer space distance or the basal spacing of the montmorillonite after adsorption, for each initial concentration of MG showed that this distance has a simulated variation by comparison with the percentage of the adsorption (Fig. 4). In the range 0-100 meq/100 g, where the adsorbed quantity is lower than the CEC, the increase in the basal space is explained by the replacement of the hydrated sodium cations by MG organic cations. However, a quantity of sodium ions compensates negative charges on the surface of the clay since the amount of dye is lower than CEC. According to the bibliographic literature, in an excess of water, the sodium ions in the interfoliair space of montmorillonite are bi or tri-hydrated ${ }^{43-47}$ and since the radius of the sphere of hydration varies from ${ }^{14,5}$ $\AA$ to $19 \AA$ (Table 4). The geometric optimization of the MG molecule in water as a solvent by the method described above, assigns a non-plane structure (Fig. 10 (a)) and a strong positive electron density around the atoms of nitrogen (Fig. 10(c)). 
Theoretical calculations, estimates the thickness of the non-plane molecule MG at $5 \AA$. The spacing of the aluminosilicate layer is $9.5 \AA^{15}$, when the amount of dye is less than $50 \mathrm{meq} / 100 \mathrm{~g}$, the basal spacing is $14,6 \AA$, hence the value of the interlayer spacing is $5,1 \AA \AA$. This value confirms the non-planar structure geometrical of the molecule, a situation corresponding to the presence of two MG molecules between the clay plates along the axis $C$ (Fig. 5(a)). When the amount of added MG increases and tends towards CEC, the presence of a small amount of sodium give rise to MG molecules a take inclined orientations with respect to the platelets of the clay (Fig. 5(b)). Which explains the increase in the basal distance to $22 \AA$. At dye concentrations greater than the CEC of the clay, the amount of sodium adsorbed is nil (negligible). In this case, an order of orientation of the MG molecules parallel to the platelet increases the basal spacing of montmorillonite see (Fig. 5(c)).

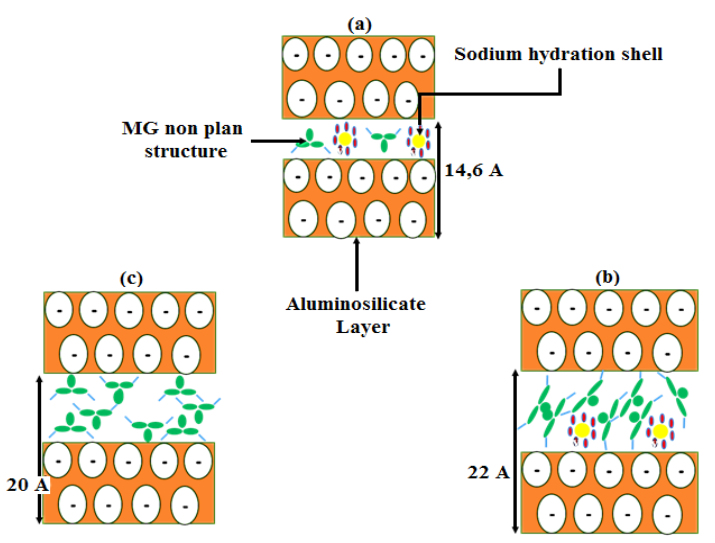

Fig. 5. Montmorillonite basal spacing after dye added, (a) $50 \mathrm{meq} / 100 \mathrm{~g}$, (b) $100 \mathrm{meq} / 100 \mathrm{~g}$, (c) $200 \mathrm{meq} / 100 \mathrm{~g}$

\section{Adsorption Isotherms}

The relationship between the amounts adsorbed Qad for MG per $100 \mathrm{~g}$ mass of Na-MMC as a function of total dye concentration in the solution is plotted in Fig. 6. The pH was measured and found to be between 3.5 and 5.75 for all samples.

The amount of adsorption increases with the increase of the MG concentration according to a linear law Qad $=\mathrm{C}_{0}$ up to the value of $110 \mathrm{meq} / 100 \mathrm{~g}$, the latter corresponds to the $C E C$ value of the sodic Montmorillonite used, as it is mentioned in theoretical model (Eq.1). At amounts less than the CEC of the clay, all the dye was essentially adsorbed, indicating a very large affinity of the dyes to Montmorillonite, as has been previously reported. The saturation level were $177 \mathrm{meq} / 100 \mathrm{~g}$ of Montmorillonite (close to $163 \%$ of the CEC). This great affinity after CEC has been demonstrated for triphenylmethane organic dyes. Other studies on the adsorption of similar dyes on the even support (the Nador Na-MMC), have shown this great affinity for the crystal violet (CV), that has a close structure to the malachite green with a maximum adsorbed quantity greater than $180 \mathrm{meq} / 100 \mathrm{~g} \mathrm{clay}^{39}$. For the Crystal Violet, G. Rytwo and als, have determined by using the model GCS the values of the binding coefficients $K$ and $K$ ' (Table 3 ), the coefficient binding value of the $K^{\prime}$ is greater than $\mathrm{K}$, which is attributed to the strong attraction between the dye and the neutral complex (Eq.3) via others bonds ${ }^{41}$.

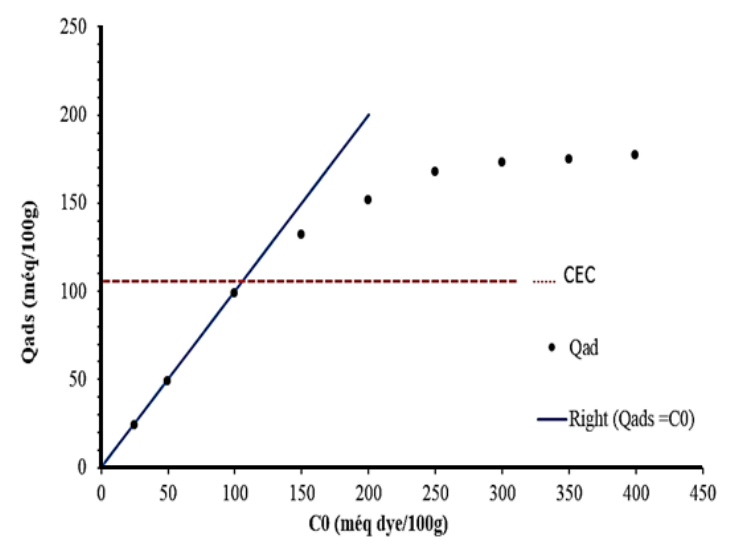

Fig. 6. Adsorption isotherm of malachite green (MG) on Na-MMC

Table 3: Binding coefficients of the some cations

\begin{tabular}{lcc}
\hline Cation & $\begin{array}{c}\text { Binding coefficient } \\
\text { for neutral complex } \\
\mathrm{Ki}\left[\mathrm{M}^{-1}\right]^{15,27}\end{array}$ & $\begin{array}{c}\text { Binding coefficient } \\
\text { for charged complex } \\
\mathrm{K}_{\mathrm{i}}\left[\mathrm{M}^{-1}\right]^{15}\end{array}$ \\
\hline Lithium $\left(\mathrm{Li}^{+}\right)$ & 0,6 & - \\
Sodium $\left(\mathrm{Na}^{+}\right)$ & 1 & - \\
Potassium (K+) & 2 & - \\
Cesium $\left(\mathrm{Cs}^{+}\right)$ & 200 & - \\
Crystal violet $(\mathrm{CV})$ & $10^{6}$ & $8.10^{9}$ \\
\hline
\end{tabular}

It is thus deduced that the specific absorption (Eq.1) requires that the surface of the clay have high affinity to the Triphenylmethane organic dyes such as crystal violet ${ }^{15,39}$ and MG in our work. From the previous results, we can conclude that montmorillonite from Nador (North east of Morocco) show superior properties for the adsorption of our dye MG compared to other clays such as montmorillonite Wyoming SWy-111,15, 31 . 


\section{Effect of various alkali chloride salts on equilibrium MG adsorption}

The effect of various metals alkali chloride salts on Malachite green removal by Na-MMC has been systematically investigated and the results are presented in Fig. 7. When a maximum quantity $\left(\mathrm{C}_{0}=350 \mathrm{meq} / 100 \mathrm{~g}\right)$ of dye was added. It has be found that the type of cations has a significant effect on malachite green removal. The removal rate of malachite green decreases with the introduction of cesium and potassium inorganic cations while it slightly increases in the presence of lithium chloride salt and sodium chloride. This can be explained by the competence of inorganic cations to be adsorbed onto negative sites of montmorillonite. That may decrease the amount of organic molecules MG adsorbed from the first layer to the clay surface when the initial dye concentration is below the CEC (specific adsorption Eq.1). The results have been analyzed in the framework of the model GCS (Nir $1984,1986)^{27,48,49}$, that has been already employed for the study of specific adsorption to Montmorillonite of $\mathrm{Li}^{+}, \mathrm{Na}^{+}, \mathrm{K}^{+}, \mathrm{Cs}^{+}$and of the hydration sphere for each of the inorganic cations. Table 4 shows that the decrease of the MG adsorption in the presence of cesium or potassium is related to their values of binding coefficient $\mathrm{K}$ (Table 3 ). Lithic and sodium montmorillonites show similarities in the relative abundances of different hydration states ${ }^{43,50}$. This can be explained in particular by the ionic radiation sizes and hydration energies, which are close enough for the two cations. Although they have not determined the basal distance, Berend and als demonstrated that the tri-hydrated state is likely to form in lithic montmorillonites for very high water contents (aqueous solution) ${ }^{43}$, this strong hydration decreases the attraction force to the clay surface and consequently increases the amount of MG adsorbed.

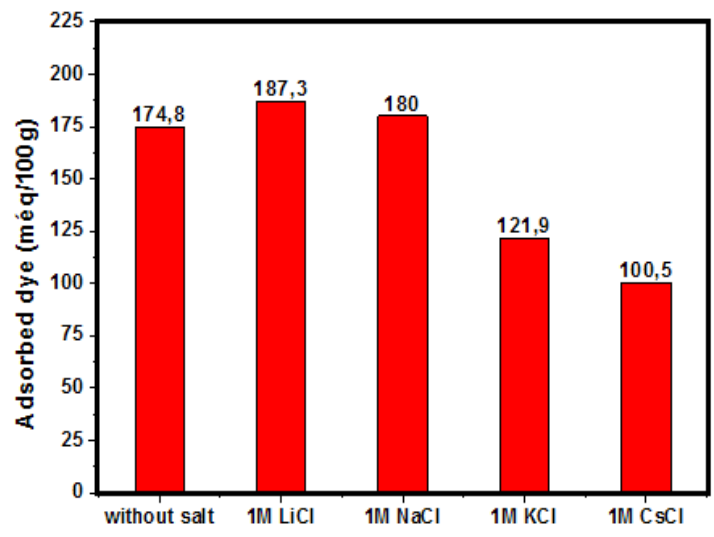

Fig. 7. Effect of $1 \mathrm{M}$ alkali chloride salt on equilibrium MG amount adsorbed onto Na-MMC

The results found in the literature show that the stable state for cesium montmorillonite is the mono-hydrated state ${ }^{43}$, hence the binding force between the clay and the cesium ions is very large compared to other cations $\mathrm{K}=200 \mathrm{M}^{-1}$ (Table 3), this strong interaction decreases the amount of MG adsorbed which explains the experimental results obtained in this work.

Potassium has an ionic radius and an intermediate hydration energy (Table 4) between those of lithium and sodium on the one hand, and those of cesium on the other hand. This certainly justifies why the tri-hydrated state is not observed experimentally in the montmorillonites potassic. In addition, the bi-hydrated and the mono-hydrated states exist only for very high water contents ${ }^{43,50,51}$. This explains the value of binding coefficient $K=2$ $\mathrm{M}^{-1}$, which has been determined by Nir et als. and also the weak interactions with respect to cesium at the surface of the clay. Therefore, the presence of potassium reduces the amount of $M G$ adsorbed because a small amount of potassium adsorbs onto the surface of the clay.

Table 4: Basal distance of montmorillonite in the presence of a single type of alkaline cation in the interlamellar space

\begin{tabular}{|c|c|c|c|c|c|}
\hline \multirow[t]{2}{*}{$\begin{array}{l}\text { Alkaline } \\
\text { cations }\end{array}$} & \multirow[t]{2}{*}{$\begin{array}{l}\text { Ionic radius } \\
(\mathrm{A})^{52,53}\end{array}$} & \multirow{2}{*}{$\begin{array}{l}\text { Hydration } \\
\text { enthalpies } \\
(\mathrm{KJ} / \mathrm{moL})^{54}\end{array}$} & \multicolumn{3}{|c|}{$\begin{array}{l}\text { Basal distance of montmorillonite in the presence of a) } \\
\text { single type alkaline cation }(\AA)\end{array}$} \\
\hline & & & Monohydrate ${ }^{45,4650,5543,44}$ & Dihydrate ${ }^{45,55,43,50}$ & Trihydrate $56,55,57$ \\
\hline $\mathrm{Li}^{+}$ & 0,76 & -520 & -- & -- & 22,5 \\
\hline $\mathrm{Na}^{+}$ & 1,02 & -406 & $12,20-12,58$ & $14,5-15,6$ & $18,10-19$ \\
\hline $\mathrm{K}^{+}$ & 1,38 & -320 & $12,40-12,65$ & $15,55-16,0$ & -- \\
\hline $\mathrm{Cs}^{+}$ & 1,67 & -264 & $12,6-12,3$ & -- & -- \\
\hline
\end{tabular}


lonic strength effect over the adsorption isotherm of MG onto Na-MMC

According to the previous results, the experimental study of the effect of the ionic strength is concentrated on the small and the large cation (lithium and cesium). The ionic strength was adjusted with $0 \mathrm{M}, 0.02 \mathrm{M}, 0.2 \mathrm{M}$ and $1 \mathrm{M}$ saline to the target values. The amount of MG removed as a function of initial dye concentrations for each ionic strength of salt (lithium chloride or cesium chloride) was measured and the results are displayed in Fig. 8 and Fig. 9.

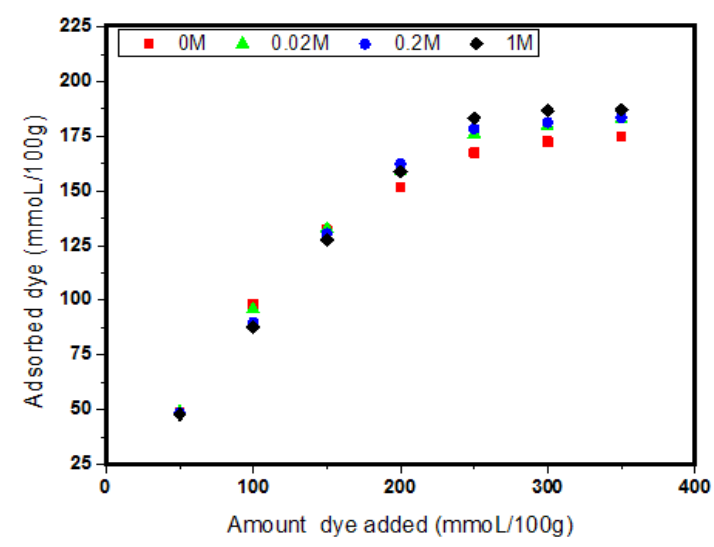

Fig. 8. The effect of different initial strength ionic of lithium chloride on MG adsorption

To simplify the analysis of the adsorption isotherms obtained based on the GCS model detailed above, the curves are decomposed in two parts, before and after $\mathrm{CEC}=109 \mathrm{meq} / 100 \mathrm{~g}$ of clay.

For initial dye concentrations below the CEC value (adsorption modeled by Equation 1), the ionic strength of lithium chloride has no effect on the adsorption isotherm (Fig. 8). The interpretation of this result is reported (Rytwo et al.,) by the very low value of the lithium (Table 3) binding constant K (Eq.1 and 2) with respect to the same dye value ${ }^{22}$, the closest reason is the strong hydration of the lithium ion ${ }^{43,53}$. Interestingly, we observe a significant decrease for $M G$ adsorbed when the ionic strength of cesium chloride increases (Fig. 9), compared to lithium. Two important factors accounting for this decrease, (1) the highest value of the ion binding constant $\mathrm{K}_{\mathrm{Cs}}>400 \mathrm{~K}_{\mathrm{Li}}$ (Table 1) and (2) his low hydration

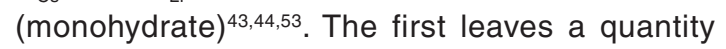
of cesium ions adsorbed on negative charges in interlamellar space. In general the clay minerals have a high affinity with the large inorganic cations ${ }^{58,59}$, studies show that the adsorption of cesium on montmorillonite is favored compared to other alkaline ions $^{27,60}$. The second factor complicates the adsorption of the MG molecules in this space, because the radius of the hydration sphere of cesium ion is smaller than the size of the MG molecule. If the amount of dye added is greater than the cation exchange capacity (CEC), a charge reversal occurs at the surface of the clay; therefore, the cations diffuse to the core of the solution by electrostatic repulsions according to the equations Eq.5 and Eq.6.

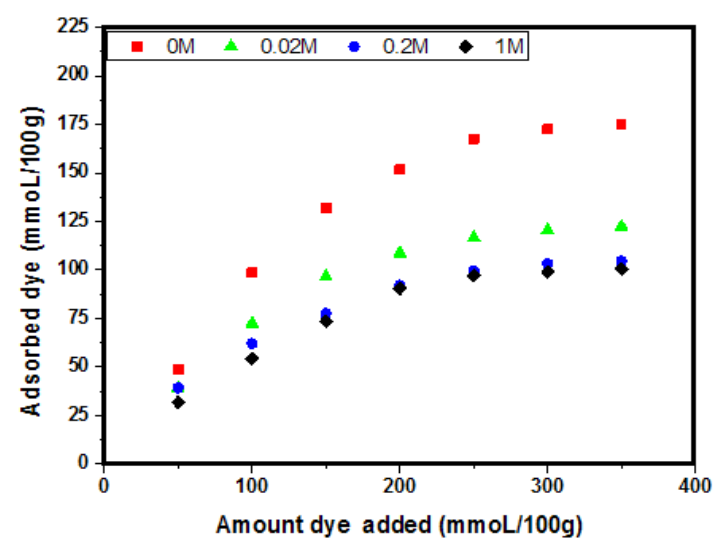

Fig. 9. The effect of different initial strength ionic of cesium chloride on MG adsorption isotherm

The increase of the ionic strength in lithium chloride favors the adsorption of the MG cations, because the increase of the concentration of lithium ions in the core of the solution (far from the positive surface), increases that of the MG at the surface of the clay. According to Table 3, the binding coefficients of the monovalent organic dyes being very important ${ }^{22}$, therefore the improvement of the MG adsorption is due to the strong interactions between the complex over face and the organic dyes (Eq.3).

\section{DFT investigations}

The full geometry optimization of MG dye were performed to investigate the structure geometry in the gas phase applying DFT/B3LYP. As illustrated in Fig. 10 (a), the optimized structure are not planar. We notice that the three fragments (1 unsubstituted and 2 substituted phenyl) of the molecule take an arrangement to reduce steric hindrance and obtaining a stable geometry. 


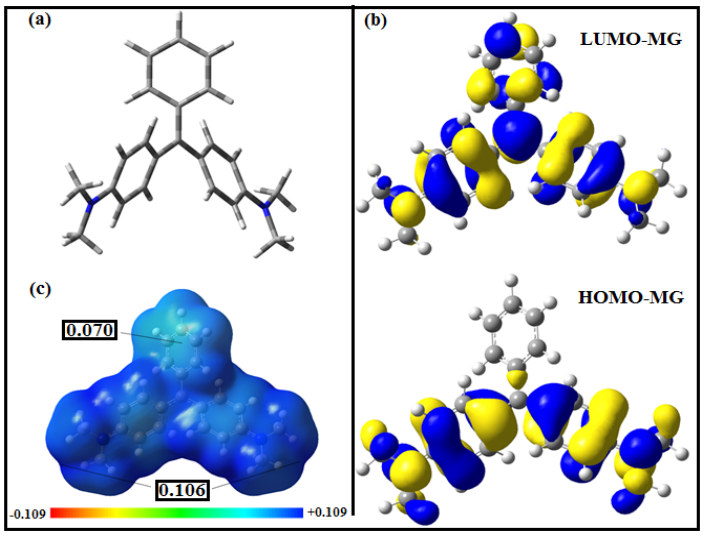

Fig. 10. a) Optimized geometry, b) HOMO and LUMO shapes, c) MEP (au)

Density Functional Theory has become a successful tool to acquire a better understanding of chemical reactivity and stability about molecules, the examination of the frontier molecular orbitals is an important key to get insights into reactivity and studying electron excitation from the highest occupied molecular orbital (HOMO) to the lowest unoccupied molecular orbital (LUMO). The LUMO corresponds to the ability of the molecule to capture an electron, the $\mathrm{HOMO}$ represents the ability to donate an electron. The HOMO-LUMO energy gap refers to the difference between the HOMO and the LUMO energy values, which indicates the charge transfer interaction taking place within the molecule.

In general, molecules with a small energy gap are attributed to a high chemical reactivity, low kinetic stability and are also defined as soft molecules, those with large energy gap have higher stability and are considered as hard molecules for the reason that they resist charge transfer and changes in their electron density and distribution ${ }^{61-64}$.

The energy of $\mathrm{HOMO}$ is directly connected to the ionization potential (IP $\left.=-\mathrm{E}_{\text {номо }}\right)$ and the energy of LUMO concern the electron affinity (EA = $\left.-E_{\text {LUMO }}\right)^{65}$. Additionally and by utilizing these values, attractive properties such as chemical hardness $(\eta)$, electrophilicity index $(\omega)$ and electronic chemical potential $(\mu)$ can be obtained. The chemical hardness is an indication of how molecule are polarizable and how much is the distortion of electron cloud in an electric field. The hardness and softness were reported in literature ${ }^{61,62}$. Chemical potential indicates the affinity of an electron to fleeing and present the first derivative of the total energy with respect to the number of electrons in a molecule ${ }^{66}$. Electrophilicity index concern the aptitude to accept electrons and it provide a quantification of the electrophilic power in a molecule ${ }^{67}$. Table 5 present the calculated parameters values and certain properties of MG (in this work) and $\mathrm{CV}^{39}$ dyes in order to compare with each other .

\begin{tabular}{|c|c|c|c|c|c|c|}
\hline \multirow[b]{2}{*}{ Dye } & \multirow[b]{2}{*}{$\mathrm{E}_{\text {номо }}$} & \multicolumn{5}{|c|}{ HOMO-LUMO } \\
\hline & & $\mathrm{E}_{\text {LUмо }}$ & gap & $\eta$ & $\mu$ & $\omega$ \\
\hline MG & -8.203 & -5.620 & 2.583 & 1.291 & -6.911 & 18.495 \\
\hline CV & -7.859 & -5.163 & 2.696 & 1.348 & -6.511 & 15.724 \\
\hline
\end{tabular}

From the reported results, the HOMO_ LUMO gap, chemical hardness $(\eta)$ and electronic chemical potential $(\mu)$ of $M G$ is comparable to thus of $\mathrm{CV}$, which indicate a similar electronic reactivity of the Triphenylmethane organic dyes. Furthermore, the higher electrophilicity index $(18.495 \mathrm{eV})$ indicate the good ability of MG to accept negative charges. This suggests that the interactions between $M G$ and the surface sites are strong and more important than those of CV .

As it is shown in Fig. 10 (b), the HOMO are mainly localized on the two substituted phenyl, the LUMO get their contribution from the whole molecule. These results suggest that the primary interaction (Eq.1) with the charged surface is assured by the totality of MG molecule; however, the secondary type of binding (Eq.3) comes from the two-amine arm parts.

MEP mapping is a very useful technique for predicting favorable sites for electrophilic and nucleophilic reactions or for revealing preferred sites for non-covalent electrostatic interactions. An isosurface of electron density mapped with electrostatic surface potential represents the size, shape, charge density, the electrophilic sites, nucleophiles, hydrogen bonds and coordination sites in the molecule. The mapped electrostatic potential (MEP) are normally represented by different colors and the increasing order of their magnitude is: red <orange <yellow <green <blue as shown in Fig. 10 (c). The red regions (electron rich or partial negative charges) of MEP are related to electrophilic reactivity and the blue regions (deficient charge or partial positive charges) of MEP are related to nucleophilic 
reactivity. The negative charges are attracted to regions with $\mathrm{MEP}>0$, while regions with $\mathrm{MEP}<0$ are repulsive. In our case, the MG molecule is an organic cation, which possess a large conjugated system with an electrostatic potential which is totally positive, and a possible electrostatic interactions is highly favorable particularly on negative charged surfaces like our clay.

When the amount of $M G$ is less than CEC, the charged surface of MMC interact with MG molecule electrostatically and the nature of MEP (Fig. 10(c)) surface suggest a good primary binding coefficient $\mathrm{K}$ (Eq.2), also the LUMO confirm that interactions can be made with the majority of $\mathrm{MG}$ molecule surface. After CEC, a charge reversal of clay occurs, in this case, $\mathrm{HOMO}-\mathrm{MG}$ can give electron density by the two substituted and linked sides (amine and $\mathrm{Pi}$ system). The interaction are concentrated and localized on only one side, in fact, the binding K' (Eq.4) becomes more important $\left(K^{\prime}>K\right)$.

\section{CONCLUSION}

In this study, a Moroccan sodic Montmorillonite was tested for its adsorption capacity to remove malachite green from aqueous solutions in the presence of various inorganic salts, ionic strength and $\mathrm{pH}$ solution. The experiments indicated that Na-MMC possesses excellent adsorption capacity for $M G$ removal from aqueous solution at $\mathrm{pH} 10$. The results also indicate that the presence of lithium or sodium salts at solution $\mathrm{pH}$ improves the maximum amount adsorbed. However, the removal rate of MG has very affected by the increase in the ionic strength of cesium chloride; at equilibrium, there is a serious decrease in the adsorbed amount. The theoretical investigation using the GCS model and the reported data was in a great agreement with experimental results, it allow us to propose the structure of the interfoliar space after the adsorption. The calculated quantum parameters explained electronically the type of interaction, which are taking place before and after CEC. MEP and molecular orbitals frontiers (HOMOLUMO) suggest the electrostatic binding with MNC.

This study demonstrated that crude bentonite extracted from a clay deposit in the Nador region (northeast of Morocco) purified and active by sodium is a promising adsorbent for environmental pollutants, even if in the presence of some inorganic salts

\section{ACKNOWLEDGMENT}

The authors are sincerely thankful to MESRSFC and CNRST-Morocco for financial support of Project PPR 15-17.

\section{Conflict of Interests}

The authors declare that there is no conflict of interests regarding the publication of this paper.

\section{REFERENCES}

1. Siracusa, V., Microbial Degradation of Synthetic Biopolymers Waste. Polymers., 2019, 11(6), 1066.

2. Bulut, E.; Özacar, M.; Oengil, I. A., Adsorption of malachite green onto bentonite: Equilibrium and kinetic studies and process design. Microporous and Mesoporous Materials., 2008, 115(3), 234-246.

3. Gupta, V.; Suhas; Ali, I.; Saini, V., Removal of rhodamine $B$, fast green, and methylene blue from wastewater using red mud, an aluminum industry waste. Industrial \& engineering chemistry research., 2004, 43(7), 1740-1747.

4. Saha, P.; Chowdhury, S.; Gupta, S.; Kumar, I., Insight into adsorption equilibrium, kinetics and thermodynamics of Malachite Green onto clayey soil of Indian origin. Chemical Engineering Journal., 2010, 165(3), 874-882.
5. Kausar, A.; Iqbal, M.; Javed, A.; Aftab, K.; Nazli, Z.-i.-H.; Bhatti, H. N.; Nouren, S., Dyes adsorption using clay and modified clay: A review. Journal of Molecular Liquids., 2018, 256, 395-407.

6. Tewari, K.; Singhal, G.; Arya, R., Adsorption removal of malachite green dye from aqueous solution., 2017, 34.

7. McKay, G.; Porter, J.; Prasad, G., The removal of dye colours from aqueous solutions by adsorption on low-cost materials. Water, Air, \& Soil Pollution., 1999, 114(3), 423-438.

8. Rajabi, M.; Mahanpoor, K.; Moradi, O., Preparation of PMMA/GO and PMMA/GO$\mathrm{Fe}_{3} \mathrm{O}_{4}$ nanocomposites for malachite green dye adsorption: Kinetic and thermodynamic studies. Composites Part B: Engineering., 2019, 167, 544-555. 
9. Ling, Y. Y.; Mohd Suah, F. B., Extraction of malachite green from wastewater by using polymer inclusion membrane. Journal of Environmental Chemical Engineering., 2017, 5(1), 785-794.

10. Bilgiç, C., Investigation of the factors affecting organic cation adsorption on some silicate minerals. Journal of Colloid and Interface Science., 2005, 281(1), 33-38.

11. Plesa Chicinas, R.; Bedelean, H.; Stefan, R.; Maicaneanu, A., Ability of a montmorillonitic clay to interact with cationic and anionic dyes in aqueous solutions. Journal of Molecular Structure., 2018, 1154, 187-195.

12. Fil, B. A., Isotherm, kinetic, and thermodynamic studies on the adsorption behavior of malachite green dye onto montmorillonite clay. Particulate Science and Technology ., 2016, 34(1), 118-126.

13. Brown, G., Crystal structures of clay minerals and related phyllosilicates. Philosophical Transactions of the Royal Society of London. Series A, Mathematical and Physical Sciences., 1984, 311(1517), 221-240.

14. Cione, A. P. P.; Neumann, M. G.; Gessner, F., Time-Dependent Spectrophotometric Study of the Interaction of Basic Dyes with Clays: III. Mixed Dye Aggregates on SWy-1 and Laponite. Journal of Colloid and Interface Science., 1998, 198(1), 106-112.

15. Rytwo, G.; Nir, S.; Margulies, L., Interactions of monovalent organic cations with montmorillonite: adsorption studies and model calculations. Soil Science Society of America Journal., 1995, 59 (2), 554-564.

16. Tabak, A.; Kaya, M.; Yilmaz, N.; Meral, K.; Onganer, Y.; Caglar, B.; Sungur, O., Pyronin $Y$ (basic xanthene dye)-bentonite composite: A spectroscopic study. Journal of Molecular Structure., 2014, 1059(0), 271-279.

17. Lagaly, G.; Ogawa, M.; Dekany, I., Clay Mineral-Organic Interactions. Handbook of Clay Science Part A: Fundamentals, $2^{\text {nd }}$ Ed., 2013, 5, 437-505.

18. Lv, G.; Li, Z.; Jiang, W.-T.; Chang, P.-H.; Liao, L., Interlayer configuration of ionic liquids in a Ca-montmorillonite as evidenced by FTIR, TGDTG, and XRD analyses. Materials Chemistry and Physics., 2015, 162, 417-424.

19. Mishael, Y. G.; Rytwo, G.; Nir, S.; Crespin,
M.; Annabi-Bergaya, F.; Van Damme, H., Interactions of monovalent organic cations with pillared clays. Journal of colloid and interface science., 1999, 209(1), 123-128.

20. Polubesova,T.; Rytwo, G.; Nir, S.; Serban, C.; Margulies, L., Adsorption of benzyltrimethylammonium and benzyltriethylammonium on montmorillonite: Experimental studies and model calculations. Clays and Clay Minerals., 1997, 45(6), 834-841.

21. Rytwo, G.; Nir, S.; Margulies, L., Adsorption and interactions of Diquat and Paraquat with montmorillonite. Soil Science Society of America Journal., 1996, 60(2), 601-610.

22. Rytwo, G.; Tavasi, M.; Afuta, S.; Nir, S., Adsorption of difenzoquat on montmorillonite: Model calculations and increase in hydrophobicity. Applied Clay Science., 2004, 24(3-4), 149-157.

23. Rytwo, G., A worksheet model for adsorption/ desorption of ions on clay surfaces., 2004, 1, 153-183.

24. Rytwo, G., Applying a Gouy-Chapman-Stern model for adsorption of organic cations to soils. Applied Clay Science., 2004, 24(3-4), 137-147.

25. Hohenberg, P.; Kohn, W., Inhomogeneous electron gas. Physical review., 1964, 136(3B), B864.

26. El Miz, M.; Akichouh, H.; Berraaouan, D.; Salhi, S.; Tahani, A., Chemical and Physical Characterization of Moroccan Bentonite Taken from Nador (North of Morocco). American Journal of Chemistry., 2017, 7(4), 105-112.

27. Nir, S.; Hirsch, D.; Navrot, J.;Banin, A., Specific adsorption of lithium, sodium, potassium, and strontium to montmorillonite: observations and predictions. Soil Science Society of America Journal., 1986, 50(1), 40-45.

28. Chowdhury, S.; Saha, P., Sea shell powder as a new adsorbent to remove Basic Green 4 (Malachite Green) from aqueous solutions: Equilibrium, kinetic and thermodynamic studies. Chemical Engineering Journal., 2010, 164(1), 168-177.

29. El Miz, M.; Akichouh, H.; Salhi, S.; El Bachiri, A.; Tahani, A., Adsorption-desorption and kinetics studies of Methylene Blue Dye on $\mathrm{Na}$-bentonite from Aqueous Solution. Journal of Applied Chemistry., 2014, 7(7), 60-78. 
30. Mohamed, E.; Akichouh, H.; Salhi, S.; El Bachiri, A.; Abdesselam, T., Adsorption-desorption and kinetics studies of Methylene Blue Dye on Nabentonite from Aqueous Solution. IOSR Journal of Applied Chemistry., 2014, 7, 60-78.

31. Margulies, L.; Rozen, H.; Nir, S., Model for competitive adsorption of organic cations on clays. Clays \& Clay Minerals., 1988, 36(3), 270-276.

32. Frisch, M.; Trucks, G.; Schlegel, H.; Scuseria, G.; Robb, M.; Cheeseman, J.; Scalmani, G.; Barone, V.; Mennucci, B.; Petersson, G., Gaussian 09, Revision C. 01,(2010) Gaussian Inc. Wallingford, CT 2009.

33. Dennington, R.; Keith, T.; Millam, J., GaussView, version 5. Semichem Inc.: Shawnee Mission, KS 2009.

34. Becke, A. D., Becke's three parameter hybrid method using the LYP correlation functional. J. Chem. Phys., 1993, 98, 5648-5652.

35. Lee, C.; Yang, W.; Parr, R., â $\in$ Development of the Colle-Salvetti conelation energy formula into a functional of the electron densityâ $\in^{\mathrm{TM}}$. Phys. Rev., 1988, 37, 785-789.

36. Cances, E.; Mennucci, B.; Tomasi, J., A new integral equation formalism for the polarizable continuum model: Theoretical background and applications to isotropic and anisotropic dielectrics. The Journal of chemical physics., 1997, 107(8), 3032-3041.

37. MarvinSketch19.19, ChemAxon (http://www. chemaxon.com)., 2019.

38. Peng, C.; Min, F.; Liu, L., Effect of $\mathrm{pH}$ on the adsorption of dodecylamine on montmorillonite: Insights from experiments and molecular dynamics simulations. Applied Surface Science., 2017, 425, 996-1005.

39. El Haouti, R.; Ouachtak, H.; El Guerdaoui, A.; Amedlous, A.; Amaterz, E.; Haounati, R.; Addi, A. A.; Akbal, F.; El Alem, N.; Taha, M. L., Cationic dyes adsorption by Na-Montmorillonite Nano Clay: Experimental study combined with a theoretical investigation using DFT-based descriptors and molecular dynamics simulations. Journal of Molecular Liquids., 2019, 290, 111-139.

40. Hu, Q. H.; Qiao, S. Z.; Haghseresht, F.; Wilson, M. A.; Lu, G. Q., Adsorption Study for Removal of Basic Red Dye Using Bentonite. Industrial \& Engineering Chemistry Research., 2006, 45(2), 733-738.

41. Johnson, S. B.; Franks, G. V.; Scales, P. J.;
Boger, D. V.; Healy, T. W., Surface chemistryrheology relationships in concentrated mineral suspensions. International Journal of Mineral Processing., 2000, 58(1), 267-304.

42. Pecini, E. M.; Avena, M. J., Measuring the Isoelectric Point of the Edges of Clay Mineral Particles: The Case of Montmorillonite. Langmuir., 2013, 29(48), 14926-14934.

43. Bérend, I.; Cases, J.-M.; François, M.; Uriot, J.-P.; Michot, L.; Masion, A.; Thomas, F., Mechanism of adsorption and desorption of water vapor by homoionic montmorillonites: 2. The $\mathrm{Li}^{+} \mathrm{Na}^{+}, \mathrm{K}^{+}$, $\mathrm{Rb}^{+}$and $\mathrm{Cs}^{+}$-exchanged forms. Clays and Clay Minerals., 1995, 43 (3), 324-336.

44. Calvet, R., Hydratation de la montmorillonite diffusion des cations compensateurs-l: Etude de l'hydratation de la montmorillonite saturée par des cations monovalents. Ann. Agron., 1973, 24(1), 77-133.

45. Cancela, G. D.; Huertas, F.; Taboada, E. R.; Sánchez-Rasero, F.; Laguna, A. H., Adsorption of water vapor by homoionic montmorillonites. Heats of adsorption and desorption. Journal of colloid and interface science., 1997, 185(2), 343-354.

46. Fu, M. H.; Zhang, Z. Z.; Low, P. F., Changes in the properties of a montmorillonite-water system during the adsorption and desorption of water: hysteresis. Clays and Clay Minerals., 1990, 38(5), 485-492.

47. Mooney, R.; Keenan, A.; Wood, L., Adsorption of water vapor by montmorillonite. II. Effect of exchangeable ions and lattice swelling as measured by X-ray diffraction. Journal of the American Chemical Society., 1952, 74(6), 1371-1374.

48. Nir, S., A model for cation adsorption in closed systems: Application to calcium binding to phospholipid vesicles. Journal of Colloid and Interface Science., 1984, 102(2), 313-321.

49. Nir, S., Specific and nonspecific cation adsorption to clays: solution concentrations and surface potentials. Soil Science Society of America Journal., 1986, 50(1), 52-57.

50. Ferrage, E.; Lanson, B.; Sakharov, B. A.; Drits, V. A., Investigation of smectite hydration properties by modeling experimental X-ray diffraction patterns: Part I. Montmorillonite hydration properties. American Mineralogist., 2005, 90(8-9), 1358-1374. 
51. Tao, L.; Xiao-Feng, T.; Yu, Z.; Tao, G., Swelling of $\mathrm{K}+, \mathrm{Na}+$ and $\mathrm{Ca2}+$-montmorillonites and hydration of interlayer cations: a molecular dynamics simulation. Chinese Physics B., 2010, 19(10), 109-101.

52. Shannon, R., Revised effective ionic radii and systematic studies of interatomic distances in halides and chalcogenides. Acta Crystallographica Section A., 1976, 32 (5), 751-767.

53. Mähler, J.; Persson, I., A Study of the Hydration of the Alkali Metal lons in Aqueous Solution., 2011, 51, 425-38.

54. Smith, D.W., lonic hydration enthalpies. Journal of Chemical Education., 1977, 54(9), 540.

55. Sato, H.; Ashida, T.; Kohara, Y.; Yui, M.; Sasaki, N., Effect of dry density on diffusion of some radionuclides in compacted sodium bentonite. Journal of Nuclear Science and Technology., 1992, 29(9), 873-882.

56. Posner, A. M.; Quirk, J. P., Changes in basal spacing of montmorillonite in electrolyte solutions. Journal of Colloid Science., 1964, 19(9), 798-812.

57. Berend, I. Les mécanismes d'hydratation de montmorillonites homoioniques pour des pressions relatives inferieures à 0.95 . Institut National Polytechnique de Lorraine., 1991.

58. Klobe, W. D.; Gast, R. G., Reactions Affecting Cation Exchange Kinetics in Vermiculite 1. Soil Science Society of America Journal., 1967, 31(6), 744-749.
59. Gast, R., Surface colloid chemistry. In'Minerals in Soil Environments'. (Eds JB Dixon and SB Weed.) Soil Science Society of America: Madison, Wisconsin., 1977, 27-73.

60. Anderson, S. J.; Sposito, G., Cesium-adsorption method for measuring accessible structural surface charge. Soil Science Society of America Journal., 1991, 55(6), 1569-1576.

61. Gázquez, J. L., Hardness and softness in density functional theory. In Chemical hardness, Springer., 1993, 27-43.

62. Pearson, R. G., Acids and bases. Science., 1966, 151(3707), 172-177.

63. Pearson, R. G., Hard and soft acids and bases. Journal of the American Chemical society., 1963, 85(22), 3533-3539.

64. Khoutoul, M.; Lamsayah, M.; Al-blewi, F. F.; Rezki, N.; Aouad, M. R.; Mouslim, M.; Touzani, R., Liquid-liquid extraction of metal ions, DFT and TD-DFT analysis of some 1, 2, 4-triazole Schiff Bases with high selectivity for $\mathrm{Pb}$ (II) and $\mathrm{Fe}$ (II). Journal of Molecular Structure., 2016, 1113, 99-107.

65. Wolinski, K.; Hinton, J. F.; Pulay, P., Efficient implementation of the gauge-independent atomic orbital method for NMR chemical shift calculations. Journal of the American Chemical Society., 1990, 112(23), 8251-8260.

66. Fukui, K., Role of frontier orbitals in chemical reactions. Science., 1982, 218(4574), 747-754.

67. Parr, R., LV; Szentpaly, S. Liu. J. Am. Chem. Soc., 1999, 121, 1922-1924. 